EESTI NSV TEADUSTE AKAДEEMIA TOIMETISED. 31. KOIDE NIFOOSIKA * MATEMAATIKA. 1982, NR. 1

ИЗВЕСТИЯ АКАДЕМИИ НАУК ӘСТОНСКОН ССР. ТОМ 31 ФИЗНКА * МАТЕМАТНКА, 1982, № 1

\title{
ВЫРАВНИВАНИЕ ГРАФИКОВ НАГРУЗКИ ПОТРЕБИТЕЛЕЙ ЭЛЕКТРОЭНЕРГИИ
}

K. JAANIMÃGI, M. MOTUS. ELEKTRIENERGIA TARBIJATE KOORMUSGRAAFIKUTE TASANDAMINE

K. JAANIM $\bar{G} I, M$, MOTUS. THE LEVELLING OF THE CONSUMERS ELECTRIC-LOAD DIAGRAMS

(Представил И. Эпик)

Вследствие уменьшения резерва генерирующих мощностей в энергосистемах создается дефицит электроэнергии в утренние и дневные максимумы нагрузки. В связи с этим возникает задача выравнивания суммарного графика нагрузки потребителей электроэнергии, который представляет собой функцию вида, изображенного на рисунке.

Аналогичный вид имеют графики нагрузки отдельных потребителей электроэнергии. Выравнивание суммарного графика нагрузки совокупности потребителей и энергосистемы в целом целесообразно проводить по потребителям, которые работают по односменному и двухсменному режимам. Перевод части нагрузки с пиковых периодов на внепиковое время $\left[{ }^{1}\right]$ положительно скажется не только на режимах работы энергосистемы, но и на показателях графиков нагрузки таких потребителей. Выравнивание графика нагрузки энергосистемы связано с дорогостоящим сооружением дополнительных генернрующих агрегатов и электростанций, с дополнительным расходом топлива и эксплуатационными затратами. Актуальность оптимизации режимов электропотребления вызвана также ухудшеннем суммарного графика нагрузки энергосистемы вследствие увеличивающегося электропотребления в сельском и коммунальном хозяйстве, транспорте и быту. Суточный график нагрузки можно регулировать как за счет промышленных предприятий, так и за счет сельскохозяйственных и других потребителей электроэнергии $\left[{ }^{2}\right]$.

В настоящей работе предлагается формализованный подход к регулированию суточных графиков нагрузки, базирующийся на результатах $\left[{ }^{3,4}\right]$. Причем рассматриваются потребители, допускающие регулирование производства в течение суток. Вызванные этим дополнительные затраты учитыва-

Схематический вид графика суммарной электрической нагрузки совокупности потребителей. $P \max -$ максимальная мощность, $t$ - время. 
ются в предлагаемой математической модели. Вопросы выравнивания графиков нагрузки отдельных предприятий изучены в $\left[{ }^{1,5}\right]$.

Обозначения: $T_{1}$ - время интенсивного потребления электроэнергии, $T_{2}$ - возможное время работы потребителей, $P_{1}$ и $P_{2}-$ суммарная максимально потребляемая мощность в среднем за час в течение $T_{1}$ и $T_{2}$.

Для выравнивания суммарного графика нагрузки в промежутке времени $T_{1}$ (т. е. для ликвидации пиков на рисунке) предложим следующую двухэтапную процедуру:

1. Распределение электроэнергии в количестве $P_{2} \cdot T_{1}$ между потребителями за период $T_{1}$, что фактически означает ограничение потребляемой мощности и электроэнергии. Причем величина ограничения представляет собой разницу $P_{1} T_{1}-P_{2} T_{1}$. В основу расчета положена модель [ $\left.{ }^{3}\right]$ с учетом условия

$$
P_{l} T_{1} \geqslant A_{l},
$$

где $A_{l}$ - необходимая $l$-му потребителю электроэнергия, чтобы избежать отключения потребителей, не имеющих возможности сдвинуть основное потребление электроэнергии в промежуток $T_{2}-T_{1}$. В рассматриваемых задачах $A_{l}$ составляет $30-40 \%$ от $P_{l}^{\max } T_{1}$ и в общем случае зависит от величины $T_{2}-T_{1}$.

Отметим, что модель $\left[{ }^{3}\right]$ упрощается, если подлежащие максимизации нелинейные функционалы $\Phi_{5}, \Phi_{6}$ заменить линейными:

$$
\Phi_{5}=\sum_{i=1}^{N} c_{5 i} x_{i}, \quad \Phi_{6}=\sum_{i=1}^{N} c_{6 i} x_{i}
$$

Для конкретных расчетов на ЭВМ в качестве подпрограмм для решения многоцелевых задач линейного программирования [ $\left.{ }^{6}\right]$ использовалась подпрограмма LSMPLX, разработанная в Институте кибернетики АН ЭССР, и пакет LPS360.

2. Распределение за $T_{2}-T_{1}$ электроэнергии $P_{1} T_{1}-P_{2} T_{1}$ между потребителями, недополучившими за период $T_{1}$ необходимого количества.

В результате будет достигнуто выравнивание суммарного графика нагрузки за период $T_{1}$. Причем каждый потребитель за каждый час этого периода использует $X_{l}^{\text {опт }} / T_{1}$ электроэнергии, где $X_{l}^{\text {опт }}$ - оптимальное количество электроэнергии, выделяемое $l$-му потребителю на период $T_{1}$. Сглаживание можно проводить по каждому часу периода $T_{1}$, а также по каждому пику в отдельности.

Предлагаемый подход нашел применение при выравнивании суммарных графиков нагрузки сельскохозяйственных потребителей электроэнергии.

\section{ЛИТ Е Р А Т У РА}

1. Надежность и экономичность электроснабжения нефтехимических заводов (под ред. В. И. Старостина), Омск, ОмПИ, 1980.

2. Голов ки н П. И., Энергосистема и потребители электрической энергин, М., «Энергия», 1979.

3. Я ан и м я г и К., Изв. АН ЭССР, Физ. Матем., 29, № 1, 105-107 (1980).

4. М т т с М., Яан и м г и К., Изв. АН ЭССР, Физ. Матем., 30, № 1, 56-57 (1981).

5. Frysincer Galen, R., IEEE Trans. Power Eng. Soc., A71.1/1-71.1/6 (1980).

6. Focke, J., Math. Operationsforsch. Statist., 4, № 5, 365-369 (1973).

Институт термофияики и электрофизики Академии наук Эстонской ССР 